\title{
Educational Intervention on Knowledge and Attitude Regarding Breast Cancer Self Examination
}

\author{
Bothyna Zakaria Murshid \\ Medical Surgical Nursing Department, College of Nursing, King Saud Bin Abdul-Aziz University for Health Sciences, King Saud \\ University, Riyadh, Saudi Arabia \\ Email address: \\ bothyna.murshid@gmail.com \\ To cite this article: \\ Bothyna Zakaria Murshid. Educational Intervention on Knowledge and Attitude Regarding Breast Cancer Self Examination. American \\ Journal of Nursing Science. Vol. 8, No. 4, 2019, pp. 181-190. doi: 10.11648/j.ajns.20190804.20
}

Received: May 20, 2019; Accepted: June 25, 2019; Published: July 9, 2019

\begin{abstract}
The aim of the study is to assess the effect of the educational intervention regarding breast cancer among high school students. A quasi-experimental pre and posttest design were utilized to fulfill the aim of this study. This study was conducted in the classrooms of the selected female high private and governmental schools. Riyadh, Kingdome of Saudi Arabia. The school was selected by simple random sampling technique and sampling units were selected consecutively. The study was conducted on 400 high school female students in in Riyadh, Saudi Arabia. A questionnaire to assess student' knowledge and attitude regarding breast cancer was developed to elicit student's information which include Data were collected from November to December 2017. Students total knowledge level of breast cancer was increased after posttest. They had a remarkable improvement in understanding of the disease which was verified with statistical significance difference than in the pretest. The educational intervention was good enough to improve student's knowledge, understanding and attitude regarding breast cancer. Educational programs are required to be implemented that utilize social and cultural factors are crucial for social awareness including such critical topics in the high school curriculum.
\end{abstract}

Keywords: Educational Intervention, Knowledge and Attitude, Breast Cancer, Breast Self-Examination, High School Students

\section{Introduction}

As per World Health Organization report, 13\% of deaths around the world are caused by cancer and it is expected that by the end of the year 2020 , the number of newly diagnosed cancer patient would increase to $40 \%$ [1]. It is one of most common cancer of females with major impact on their health which is identified as a major global health problem by WHO just being the second to lung cancer for causing deaths [2]. In an estimation of WHO more than one million new breast cancer cases are diagnosed annually worldwide of which more than half of these cases present in developing countries. In a report published in 2011 by World Health Organization expect largest increase in all type of cancer incidence in the Middle Eastern countries in coming 15 years with $70 \%$ mortality rate, compared to $40-55 \%$ in western countries [1].

Breast cancer is one among prevalent cancer in women worldwide as well in the Kingdom of Saudi Arabia. In Saudi Arabia, breast cancer account for up to $27 \%$ of all newly diagnosed female cancers $(5,378)$ in the year 2010 [3]. Saudi Cancer Registry epidemiological reports analysis stated that the crude age-standardized incidence rate in female breast cancer is increasing annually. According to the latest statistics by the National Cancer Registry (NCR) in Saudi Arabia for 2016, a percentage of $16 \%$ among Saudis were affected with breast cancer represents $29 \%$ of all women with cancer in general. These statistics considered a huge burden to the health affairs which makes health education and awareness amongst women in the community will be one of the most successful methods of prevention, early detection and treatment [4].

According to guidelines set by Saudi Center for EvidenceBased Health Care, Saudi ministry which shows the incidence of breast cancer in Saudi Arabia and marked that female are at risk of having breast cancer at any age, and there should be an awareness of breast cancer as early as possible [4]. Most of the Saudi women are diagnosed with breast cancer at more advanced stages with complication and 
metastasis indicating the need for early detection of the disease and increased awareness among the population [5]. So this early detection of disease we can improve in numbers only when the women's are thought about it as early as possible. As the high school women are at age matured enough to understand the study objective and educational intervention, then they are the ideal population to learn it faster than old-aged population. Researches have proposed that the incidence of breast cancer is increased not only due to low awareness in gold countries but certain factors such as increased levels of urbanization, increased life expectancy, and the adoption of western lifestyles also played a major role in this [6].

Morbidity and mortality are effectively reduced by early detection. Despite this participation rates in breast cancer screening activities are very low among Arab women [7, 8], due to the conservative nature of the Saudi community. Most of the women in Gulf countries hesitate and also not encouraged by family for immediate medical attention or follow up in breast cancer due to shyness until their disease becomes in late stages. Educational interventions are required for raising awareness of breast cancer in order to improve the rates of early detection, thus increasing chances of curative treatment and decrease the financial burden proper breast cancer education would include breast self-examination training, knowledge through different media, social network, as well as conference and workshops education $[5,9]$. Prevention and early detection are key to reduce the incidence and severity of many diseases [10]. It is recommended that health education should be applied continuously which involve Saudi Arab females who tend to marry at a young age according to the traditional and cultural values of the society. Therefore, proper breast cancer education and breast self-examination training should be provided involving, utilization of the different media, social network, as well as conference and workshops education.

In this study, we analyzed the implementation of an educational intervention on knowledge and attitude regarding breast cancer and breast self-examination and to assess the effect among high school students. We hypothesized that high school students who participate in the educational intervention will exhibit a higher level of knowledge regarding breast cancer and breast self-examination in the post-intervention test.

\section{Materials and Method}

\subsection{Ethical Approval}

The present research study was approved from the research unit of the college of nursing, dean of the college and king saud Medical Research Center, KSA. The participants were informed about the purpose of the study, and that student who accepted to participate were asked to give written informed consent. Confidentiality of all participants was maintained at all time of the study period.

\subsection{Research Design}

A quasi-experimental pre and posttest design were utilized to fulfill the aim of this study.

\subsection{Setting}

This study was conducted in the classrooms of the selected female high private and governmental schools. Riyadh, Kingdome of Saudi Arabia. The school was selected by simple random sampling technique and sampling units were selected consecutively.

\subsection{Sample}

According to Ministry of Education registry for the year 1436-1435; there were 59647 female students in the third grade of high schools at Riyadh city. Using power analysis to calculate the study sample size, it was found that 400 female students will be a representative sample, with confidence level $95 \%$ and margin of error 5\%. Randomly high schools were chosen randomly from five private and five governmental schools. Then all students in the $3^{\text {rd }}$ year of high school were invited to participate in the study because students are more mature, about to graduate, join colleges and get married so, increase their knowledge at this age will help them to adopt preventive measures more efficiently.

\subsection{Inclusion and Exclusion Criteria}

All students who were attended the school day of data collection and agree to participate in the study were enrolled.

\subsection{The Tool of Data Collection}

A validated structured questionnaire was used to obtain the purpose of the study. In addition to demographic data such as age, previous knowledge and source of information regarding breast cancer and the presence of a family member with breast cancer, students' knowledge and attitude toward breast cancer questionnaire were used. The questionnaire was developed by the investigator after an extensive thorough review of related literature and previous studies with similar objectives. Then a group of 4 faculties in medical/surgical were invited to evaluate the questioner, their feedback was considered in the final version. The questionnaire developed in the Arabic language for easy use by high school student and consisted of 3 main parts; Part one socio-demographic data, Part two is related to knowledge regarding breast cancer that contains 63 questions on a-3 points Likert scale with (2) correct answer, (1) wrong answer and (0) don't know. To better present knowledge, scores were presented as, poor, fair and good. The questionnaire comprises nine questions related to general knowledge of breast cancer; national and Riyadh incidence, general physical and psychological effect, definition, 14 questions related to risk factors that may cause breast cancer, 8 questions related to signs and symptoms of breast cancer, 9 questions related to methods of breast cancer diagnosis and treatment, 11 questions related to effects and complication of breast cancer treatment, and 12 questions 
related to measures of breast cancer prevention, the total scores was obtained then converted into total score percent. The level of knowledge was categorized as poor $(<50 \%)$, fair $(50-75 \%)$ and good $(>75 \%)$. Part three is related to student knowledge regarding breast self-examination which comprises 9 questions related to; time of breast selfexamination, up to normal finding, and when to report to the physician. Part four of the questionnaire is concerned with student' attitude toward breast cancer, it contains 22 statements with 3 points scale; agree (3), neutral (2) and disagree (1) the obtained total score of students attitude ranged from 22 to 66 which categorized as positive and negative attitude where positive attitude equal to 44 scores and above while negative attitude is less than 44 score.

\subsection{Pilot Study}

Before performing the main study with large sample size, we did perform it on five students to test the clarity and applicability of the questions, and no major concerns were found. The study questionnaire was tested by 4 medicalsurgical nursing faculties for validity through revision. Reliability was tested before the main data analysis and was reported as 0.90 for knowledge and 0.83 for attitude.

\subsection{Intervention and Data Collection}

The study was done in 4 phases. First phase developing of the study questionnaire and the educational intervention contents that cover all items related to breast cancer such as; general information, incidence in KSAU, causes, signs and symptoms risk factors, treatment, complication, prevention, and more emphasis was given to breast self-examination time technique and symptom that indicates urgent seeking of medical attention. The contents of the educational intervention were prepared by the investigator after extensive reviewing of related textbooks and media. The plan of the educational sessions and time of sessions were communicated with the principle of the schools and the teachers of the classes as well. The educational intervention session was for half day long and also covered the question from participants. The second phase was the pretest that assesses the students' knowledge, perception and attitude regarding breast cancer. Students were told about the purpose of the study and the questionnaire was applied to all student included in the study. There was no limited time to complete the questionnaire. The third phase was the implementation of the educational intervention at a onetime session to all participants by the investigator itself which consists of; power point presentation of the educational session regarding cancer breast which covers all items of the disease followed by 5 minutes video presentation illustrated the proper time and technique and up the normal finding of breast selfexamination. Students were divided into groups of 20 students into groups. Each educational session lasted 1 hour and included illustrations, questions, brainstorming, and active discussion, students were encouraged to interact and ask questions and give comments. Sessions were provided in the Arabic language. The fourth phase was posttest after the educational sessions.

\subsection{Statistical Analysis}

Data from the study tools was categorized, tabulated; analyze using the SPSS software version 21. Descriptive statistics (frequencies, means, and standard deviations) were utilized to describe the demographic variables. Inferential statistics (t-test. Paired sample t-tests) were used to compare two sets of data (pre-intervention and post-intervention). Spearman's rho was used to determine the relationship between student knowledge and attitude with sociodemographic data. A significance level value was considered when $\mathrm{p}<0.05$.

\section{Result}

An equal number of 200 single female of third-grade high school student from the private and government sector participated in the study with the age ranged from 17-19 years old. Participants took an average of $20 \pm 7$ Minutes for filling the questionnaires.

The main sources of a student information regarding breast cancer were internet $27.8 \%$ followed by awareness campaign $25.3 \%$ and friends $14 \%$, in addition; $10 \%$ of the student has a family member with breast cancer. Results presented that only small percent $14.75 \%$ of the student have good knowledge level pre-intervention while the majority of the $84.00 \%$ have good knowledge level after the intervention and there was a highly significant difference in knowledge level pre and post the educational intervention where $\mathrm{P}=0.00$. Moreover; the table illustrated that more than fourth of the student $28.25 \%$ have poor total knowledge levels about risk factors that may cause breast cancer which has been decreased dramatically after the intervention to $2.50 \%$ and the increased knowledge level was highly significant difference pre and post the educational intervention where $\mathrm{P}=0.00$. As related to total knowledge levels of students related to signs symptoms of breast cancer; the same table showed that more than half $59.25 \%$ of the student while the majority of them $96.50 \%$ have good knowledge in the pre and post the educational intervention respectively and the difference was statistically significant (table 1).

It is indicated in a study that less than third $31.25 \%$ of the studied student have fair knowledge level about methods of diagnosis and treatment of breast cancer compared to only small percent $8.50 \%$ of them while the difference was statistically significant at $\mathrm{P}=0.00$ in the pre and post educational intervention respectively. Regarding total knowledge levels of students about the side effect of chemo and radiotherapy and complication of breast cancer; the same table presented that only $23.25 \%$ of the student have good knowledge pre compared to most of the $84.25 \%$ post the intervention.

For measures of breast cancer prevention; $17.50 \%$ of the student and none of them have poor total knowledge pre and post the intervention respectively while $60 \%$ of them have 
good knowledge compared to $99 \%$ and there was a highly significant difference pre and post the intervention respectively.

As related to the total knowledge level of high school student regarding all knowledge items of breast cancer; it was found that the knowledge level ranged from 6-136 and SD $88.52 \pm 21.55$ which has been increased to $77-144$ and SD $130.29 \pm 14.09$ in the pre and post the intervention respectively and there was a highly significant difference as $\mathrm{P}=0.00$. More than third $41 \%$ of the student doesn't know the proper time of breast self-examination compared to only a small percent $10.75 \%$ in the pre and post intervention respectively. In addition; same table illustrated that more than half of the students $52.75 \%, 54.5 \%, 57 \%$, and $57 \%$ know the right answer in the pre-intervention compared to most of the student in the post-intervention $94.25 \%, 96.00 \%$, $94.00 \%$ and $96.00 \%$ regarding presence of itching or scaly ulcers in the nipple, nipple secretion, retracted nipple, and continuous pain in the breast respectively as a warning signs which indicated medical attention (table 2).

On the other hand; the same table illustrated that the mean of the student knowledge was 0-18 and SD 11.81 \pm 4.66 which has been increased to 7-18 and SD $16.80 \pm 1.98$ in the pre and post intervention respectively, moreover; less than half $46.25 \%$ of the student have good knowledge compared to most of the $93.5 \%$ in the pre and post intervention respectively and only $1 \%$ of them have total fair knowledge level in the postintervention and the difference was statistically highly significant in all items of breast self-examination and the total knowledge level where $\mathrm{P}=0.00$.

Results demonstrated that the range of student attitude was 36-63 in pre-intervention which has been increased to 44-63 in the post-intervention. In addition, table 3 showed that only small percent $4.3 \%$ of the student has a negative attitude regarding breast cancer pre the intervention while all of the $100 \%$ have a positive attitude post the educational intervention and the difference in the student attitude pre and post-intervention were highly significant as $\mathrm{P}=0.00$ (table 3 ).

Table 4 showed that in the pre-intervention; less than half $41.18 \%$ of the student who has poor total knowledge level have a negative attitude while near third $31.59 \%$ of them who have good knowledge level have a positive attitude and the difference in total knowledge and total attitude level was highly significant where $\mathrm{P}=0.00$. For the post-intervention; it was found that most of the student $93.21 \%$ with a positive attitude have good total knowledge level and the difference in total knowledge level and total attitude level was highly significant where $\mathrm{P}=0.00$ in the posttest.

More than third $36.36 \%$ of the private school student has good knowledge compared to near two-third $63.44 \%$ of a governmental school student in the pre-intervention while in the post-intervention same percent $50 \%$ of them have fair and good knowledge. Regarding to age same table presented that; more than half $58.68 \%$ and majority $84.62 \%$ of the students who aged 17 years old have good and fair knowledge in the pre and post intervention respectively while none of the student and very small percent $0.53 \%$ of the student who is
19 years old have good knowledge in the pre or postintervention. In addition, the same table showed that less than half of the students $44.63 \%$ with good knowledge get their knowledge from the awareness campaign in the pre while more than third of the student $34.62 \%$ with fair knowledge level obtain their information from the television in the postintervention. There was a significant statistical difference between the type of school, age, the source of knowledge and total knowledge level in the pre-intervention where $\mathrm{P}=0.001$, 0.00 and 0.00 respectively and between age, the source of knowledge and total knowledge level in the post-intervention where $\mathrm{P}=0.043,0.00$ respectively (table 5).

Majority of the studied student $88.24 \%$ in the private school compared to a small percent $11.76 \%$ of governmental school student has a negative attitude in the pre-intervention and the difference is significant at $\mathrm{P}=0.002$. Regarding age same table proved that majority $88.24 \%$ of student who aged 18 years have negative attitude comparing to more than half $63.71 \%$ of student who aged 17 years have a positive attitude in the pre-intervention and the difference is significant $\mathrm{P}=0.00$. As related knowledge source; same table showed that highest percent $28.98 \%$ and $25.07 \%$ of the student with a positive attitude gained their knowledge from the internet and awareness campaign respectively in the pre-intervention and the difference is significant as $\mathrm{P}=0.00$ while in the postintervention almost the same percent $27.8 \%$ and $25.3 \%$ were reported by the student as the internet and awareness campaign respectively is the main source of information (table 6).

There was a correlation between students' age, type of school and total mean scores of knowledge and attitude toward breast cancer pre and post-intervention as $\mathrm{P}=<0.05$ (table 7).

\section{Discussion}

Cancer is a leading cause of death in the world, with breast cancer being most common among women globally $[1,9,11]$. Due to social restriction among women in the gulf the awareness regarding self-healthcare is at very low and thus disease like breast cancer affects Saudi women at an early age compared to developed countries, imposing socioeconomic burdens. The present study showed that the mean age of the participant student was 17-19 years; similar study [12] titled; Educational Intervention Program on Knowledge Regarding Breast Self-Examination Among Higher Secondary School Girls of Biratnagar stated that the majority of respondents were from age group 17-19 years, the main source of information in the present study is the internet and the awareness campaign which may be attributed to the increased use of the internet nowadays especially between teenagers and the conduction of annually National campaign for breast cancer awareness in Riyadh, [11] was in the and found that the source of information for a lot of the women about breast cancer was awareness campaigns, also mentioned that major source of information of the participant is the media [12]. 
The results of the present study showed a highly significant improvement in student knowledge level related to breast cancer and breast self-examination from pre to posttest as $\mathrm{p}<0.05$, supported the results of earlier published report that stated assessment revealed that the targeted education intervention was effective in improving knowledge of breast cancer immediately post-education [13], in addition agreed with the present study and mentioned that the scores for the final visit were higher for the intervention group than the control group $(p<0.05)$ [14]. Moreover in his study proved significant improvement in the Health Belief Model group in terms of knowledge about breast cancer and breast self-examination, $[15,16]$ agreed with the present result and stated that statistically significant improvement in the studied women's knowledge $(\mathrm{p}<0.05)$ and practice $(83.3 \%)$ about breast self-examination immediately after implementation of the intervention program compared to the pre-program scores, in addition a study was conducted in Riyadh, King of Saudi Arabia and revealed that almost half of the women were not aware of breast cancer, breast self-examination or mammography [11].

Moreover; the results of the present study was in line with many other studies done in different Arab and western countries and address the effect of an educational intervention on knowledge and practice of breast selfexamination [17-23]. However this was the first study which was undertaken on the higher school girls from this region and as we know the learning at this stage would have greater impact later on.

The result of the present study illustrated that student total level of attitude has been improved post the intervention which was in agreed with earlier published reports who reported significant improvement in the intervention group attitudes and behavior after education also supported the same result and added; the difference in the students' knowledge, attitude and practice was statistically significant $(p<0.001)$ after the education program [24, 25]. More recently, [26] was in line with the current result and stated breast self-examination educational interventions are also effective because the educational interventions improve knowledge and confidence while promoting attitude and behavior modification among women.

The result of the present study revealed that there was a correlation between students' age, type of school and total mean scores of knowledge and attitude toward breast cancer pre and post-intervention, [27] was in line and emphasized the significant relationship between socio-demographic data with women's beliefs and behavior towards breast cancer prevention. The main difference of our study to all other studies was the age group what we selected for this study. Most of earlier reports were published using the middle-aged group of women's above 25 and/or 30 years age, whereas our study used a population sample of high school women's with age ranging between 17-19 years.

\section{Conclusion}

The educational intervention was highly effective as the knowledge and attitude score was significantly increased after the intervention for high school female students. Among the various socio-demographic variables students' age, and type of school found to be effective with knowledge and attitude score. It was very evident from the study analysis that educational intervention plays a major role in improving the health care knowledge and promotes preventive measures among society including females. We emphasize to implement a plan on appropriate health education regarding breast cancer prevention and breast self-examination which would enable our women's population to be self-motivated regarding their health. Such awareness is going to reduce the mortality and morbidity due to breast cancer among our women.

Conduction of awareness campaigns through mass and social media, television, and internet. Moreover, special awareness sessions need to be conducted in institutions like schools, colleges, universities, malls where a high proportion of women can be easily reached. Women should be encouraged to perform monthly breast self-examination and getting mammography done at appropriate intervals.

Table 1. Distribution of student regarding their knowledge levels regarding items of breast cancer pre and post the educational intervention.

\begin{tabular}{|c|c|c|c|c|c|}
\hline \multirow{3}{*}{ Knowledge Items levels } & \multicolumn{4}{|c|}{ The studied students $(n=400)$} & \multirow{3}{*}{$\chi^{2} \mathbf{P}$} \\
\hline & \multicolumn{2}{|c|}{ Pre } & \multicolumn{2}{|l|}{ Post } & \\
\hline & $\mathbf{N}$ & $\%$ & $\mathbf{N}$ & $\%$ & \\
\hline \multicolumn{6}{|c|}{ Knowledge about breast cancer } \\
\hline Poor & 146 & 36.5 & 20 & 5 & \multirow{3}{*}{$385.290 .00^{*}$} \\
\hline Fair & 195 & 48.75 & 44 & 11 & \\
\hline Good & 59 & 14.75 & 336 & 84 & \\
\hline Range & \multicolumn{2}{|l|}{$(0-16)$} & \multicolumn{2}{|l|}{$(5-18)$} & $\mathrm{t}=26.07$ \\
\hline Mean \pm SD & \multicolumn{2}{|l|}{$9.04 \pm 3.48$} & \multicolumn{2}{|l|}{$14.97 \pm 2.94$} & $\mathrm{P}=0.00^{*}$ \\
\hline \multicolumn{6}{|c|}{ Factors that may cause breast cancer } \\
\hline Poor & 113 & 28.25 & 10 & 2.5 & \multirow{3}{*}{$254.110 .00^{*}$} \\
\hline Fair & 172 & 43 & 55 & 13.75 & \\
\hline Good & 115 & 28.75 & 335 & 83.75 & \\
\hline Range & \multicolumn{2}{|l|}{$(0-28)$} & \multicolumn{2}{|l|}{$(8-28)$} & $\mathrm{t}=22.20$ \\
\hline Mean \pm SD & \multicolumn{2}{|l|}{$16.52 \pm 6.16$} & \multicolumn{2}{|l|}{$24.81 \pm 4.22$} & $\mathrm{P}=0.00 *$ \\
\hline
\end{tabular}




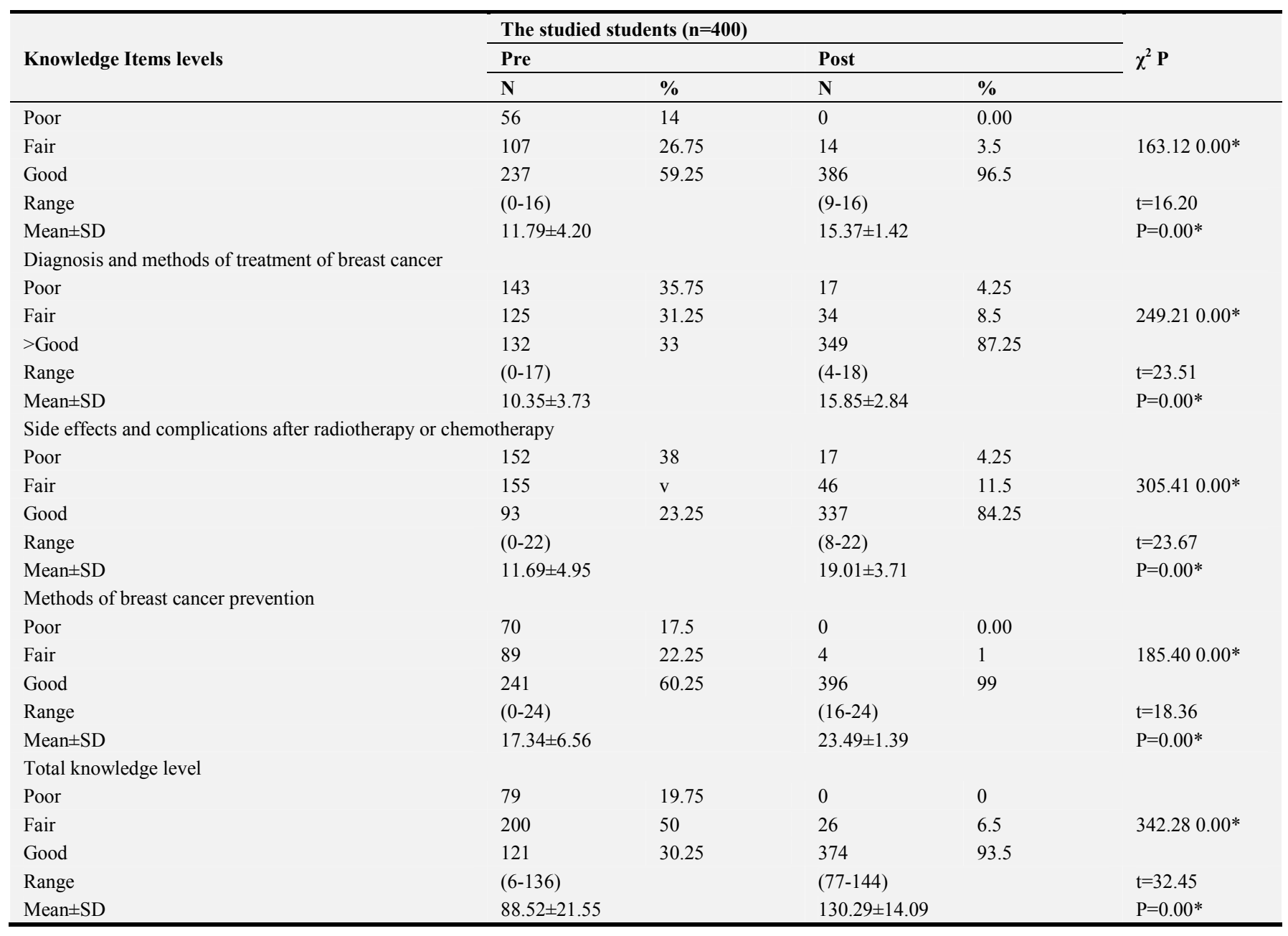

* Significant at $\mathrm{P}<0.05$.

Table 2. Distribution of the students regarding their knowledge about breast self examination pre and post intervention.

\begin{tabular}{|c|c|c|c|c|c|}
\hline \multirow{3}{*}{ Breast Self-Examination } & \multicolumn{4}{|c|}{ The studied students $(n=400)$} & \multirow{3}{*}{$\chi^{2} \mathbf{P}$} \\
\hline & \multicolumn{2}{|l|}{ Pre } & \multicolumn{2}{|c|}{ Post } & \\
\hline & $\mathbf{N}$ & $\%$ & $\mathbf{N}$ & $\%$ & \\
\hline \multicolumn{6}{|c|}{$\mathrm{BSE}$ is performed on 3-5 day before the menstruating } \\
\hline Don't know & 165 & 41.25 & 43 & 10.75 & \multirow{3}{*}{$147.660 .00 *$} \\
\hline No & 182 & 45.5 & 169 & 42.25 & \\
\hline Yes & 53 & 13.25 & 188 & 47 & \\
\hline \multicolumn{6}{|c|}{ Warning signs which indicated medical attention } \\
\hline \multicolumn{6}{|c|}{ Mass or hard lump in breast } \\
\hline Don't know & 58 & 14.5 & 0 & 0 & \multirow{3}{*}{$76.260 .00^{*}$} \\
\hline No & 38 & 9.5 & 16 & 4 & \\
\hline Yes & 304 & 76 & 384 & 96 & \\
\hline \multicolumn{6}{|c|}{ Swelling, heat, redness or change in breast skin } \\
\hline Don't know & 48 & 12 & 0 & 0 & \multirow{3}{*}{$106.330 .00^{*}$} \\
\hline No & 65 & 16.25 & 9 & 2.25 & \\
\hline Yes & 287 & 71.75 & 391 & 97.75 & \\
\hline \multicolumn{6}{|c|}{ Change size or shape of breast } \\
\hline Don't know & 110 & 27.5 & 4 & 1 & \multirow{3}{*}{$150.980 .00^{*}$} \\
\hline No & 44 & 11 & 10 & 2.5 & \\
\hline Yes & 246 & 61.5 & 386 & 96.5 & \\
\hline \multicolumn{6}{|c|}{ Small dimpling or wrinkles in the breast skin } \\
\hline Don't know & 86 & 21.5 & 22 & 5.5 & \multirow{3}{*}{$98.710 .00^{*}$} \\
\hline No & 73 & 18.25 & 16 & 4 & \\
\hline Yes & 241 & 60.25 & 362 & 90.5 & \\
\hline \multicolumn{6}{|c|}{ Itching, or scaly ulcers or rash on the nipple } \\
\hline Don't know & 108 & 27 & 17 & 4.25 & \multirow{2}{*}{$177.760 .00 *$} \\
\hline No & 81 & 20.25 & 6 & 1.5 & \\
\hline
\end{tabular}




\begin{tabular}{|c|c|c|c|c|c|}
\hline \multirow{3}{*}{ Breast Self-Examination } & \multicolumn{4}{|c|}{ The studied students $(n=400)$} & \multirow{4}{*}{$\chi^{2} \mathbf{P}$} \\
\hline & \multicolumn{2}{|c|}{ Pre } & \multicolumn{2}{|l|}{ Post } & \\
\hline & $\mathbf{N}$ & $\%$ & $\mathbf{N}$ & $\%$ & \\
\hline Yes & 211 & 52.75 & 377 & 94.25 & \\
\hline \multicolumn{6}{|l|}{ Secretions from the nipple } \\
\hline Don't know & 109 & 27.25 & 10 & 2.5 & \\
\hline No & 73 & 18.25 & 6 & 1.5 & $184.960 .00 *$ \\
\hline Yes & 218 & 54.50 & 384 & 96 & \\
\hline \multicolumn{6}{|l|}{ Retracted nipple } \\
\hline Don't know & 101 & 25.25 & 13 & 3.25 & \\
\hline No & 71 & 17.75 & 11 & 2.75 & $148.090 .00 *$ \\
\hline Yes & 228 & 57 & 376 & 94 & \\
\hline \multicolumn{6}{|l|}{ Continuous pain in the breast } \\
\hline Don't know & 109 & 27.25 & 4 & 1 & \\
\hline No & 63 & 15.75 & 12 & 3 & $172.010 .00^{*}$ \\
\hline Yes & 228 & 57 & 384 & 96 & \\
\hline \multicolumn{6}{|l|}{ Total knowledge level } \\
\hline Poor & 75 & 18.75 & 4 & 1 & \\
\hline Fair & 140 & 35 & 22 & 5.5 & $213.660 .00^{*}$ \\
\hline Good & 185 & 46.25 & 374 & 93.5 & \\
\hline Range & $(0-18)$ & & $(7-18)$ & & $\mathrm{t}=19.74$ \\
\hline Mean \pm SD & $11.81 \pm 4.66$ & & $16.80 \pm 1.98$ & & $\mathrm{P}=0.00^{*}$ \\
\hline
\end{tabular}

* Significant at $\mathrm{P}<0.05$.

Table 3. Distribution of the studied students regarding their total level of attitude of breast cancer pre and post the educational intervention.

\begin{tabular}{|c|c|c|c|c|c|}
\hline \multirow{3}{*}{ Total attitude and perception level } & \multicolumn{4}{|c|}{ The studied students $(n=400)$} & \multirow{3}{*}{$\chi^{2} \mathbf{P}$} \\
\hline & \multicolumn{2}{|c|}{ Pre } & \multicolumn{2}{|l|}{ Post } & \\
\hline & $\mathbf{N}$ & $\%$ & $\mathbf{N}$ & $\%$ & \\
\hline$<44$-ve attitude & 17 & 4.3 & 0 & 0 & FE \\
\hline$\geq 44+v e$ attitude & 383 & 95.8 & 400 & 100 & $0.00^{*}$ \\
\hline Range & $(36-63)$ & & $(44-63)$ & & $\mathrm{t}=6.265$ \\
\hline Mean \pm SD & $53.30 \pm 5.76$ & & $55.58 \pm 4.45$ & & $\mathrm{P}=0.00^{*}$ \\
\hline
\end{tabular}

$<50 \%$-Ve attitude $\geq 50 \%+$ Ve attitude.

FE: Fisher's Exact test.

* Significant at level $\mathrm{P}<0.05$.

Table 4. Correlation between total knowledge and total attitude level of studied students regarding breast cancer pre and post educational intervention.

\begin{tabular}{|c|c|c|c|c|c|}
\hline \multirow{3}{*}{ Total knowledge level } & \multicolumn{4}{|c|}{ Total attitude and perception level $(n=400)$} & \multirow{3}{*}{$\chi^{2} \mathbf{P}$} \\
\hline & \multicolumn{2}{|c|}{-ve attitude $(n=17)$} & \multicolumn{2}{|c|}{$+v e$ attitude $(n=383)$} & \\
\hline & $\mathbf{N}$ & $\%$ & $\mathbf{N}$ & $\%$ & \\
\hline \multicolumn{6}{|l|}{ Pre } \\
\hline Poor & 7 & 41.18 & 72 & 18.8 & \multirow{3}{*}{$9.770 .008 *$} \\
\hline Fair & 10 & 58.82 & 190 & 49.61 & \\
\hline Good & 0 & 0 & 121 & 31.59 & \\
\hline $\mathrm{r}, \mathrm{P}$ & \multirow{2}{*}{\multicolumn{4}{|c|}{$0.354,0.00 * *$}} & \\
\hline Post & & & & & \multirow{4}{*}{ FE 0.616} \\
\hline Fair & 0 & 0 & 26 & 6.79 & \\
\hline Good & 17 & 100 & 357 & 93.21 & \\
\hline $\mathrm{r}, \mathrm{P}$ & -0.1 & & & & \\
\hline
\end{tabular}

*Correlation is significant at level $\mathrm{P}<0.05$.

** Highly significant at level $\mathrm{P}<0.01$.

Table 5. Correlation between socio demographic characteristics of the studied students and their total level of knowledge regarding breast cancer pre and post the educational intervention.

\begin{tabular}{|c|c|c|c|c|c|c|c|}
\hline \multirow{4}{*}{ Characteristics } & \multicolumn{7}{|c|}{ Total knowledge level $(n=400)$} \\
\hline & \multicolumn{6}{|c|}{ Pre } & \multirow{3}{*}{$\chi^{2} \mathbf{P}$} \\
\hline & \multicolumn{2}{|c|}{ Poor $(n=79)$} & \multicolumn{2}{|c|}{ Fair $(n=200)$} & \multicolumn{2}{|c|}{ Good $(n=121)$} & \\
\hline & $\mathbf{N}$ & $\%$ & $\mathbf{N}$ & $\%$ & $\mathbf{N}$ & $\%$ & \\
\hline \multicolumn{8}{|l|}{ School } \\
\hline Private & 47 & 59.49 & 109 & 54.5 & 44 & 36.36 & \multirow{3}{*}{$13.470 .001 *$} \\
\hline Government & 32 & 40.51 & 91 & 45.5 & 77 & 63.64 & \\
\hline \multicolumn{7}{|l|}{ Age (in years) } & \\
\hline 17 years & 32 & 40.51 & 143 & 71.5 & 71 & 58.68 & \multirow{2}{*}{$26.830 .00^{*}$} \\
\hline 18 years & 47 & 59.49 & 55 & 27.50 & 50 & 41.32 & \\
\hline
\end{tabular}




\begin{tabular}{|c|c|c|c|c|c|c|c|}
\hline \multirow{4}{*}{ Characteristics } & \multicolumn{7}{|c|}{ Total knowledge level $(n=400)$} \\
\hline & \multicolumn{6}{|c|}{ Pre } & \multirow{3}{*}{$\chi^{2} \mathbf{P}$} \\
\hline & \multicolumn{2}{|c|}{ Poor $(n=79)$} & \multicolumn{2}{|c|}{ Fair $(n=200)$} & \multicolumn{2}{|c|}{ Good $(n=121)$} & \\
\hline & $\mathbf{N}$ & $\%$ & $\mathbf{N}$ & $\%$ & $\mathbf{N}$ & $\%$ & \\
\hline 19 years & 0 & 0 & 2 & 1 & 0 & 0 & \\
\hline \multicolumn{8}{|l|}{ Sources of knowledge } \\
\hline None & 13 & 16.46 & 30 & 15 & 7 & 5.79 & \multirow{7}{*}{$57.270 .00 *$} \\
\hline Net & 24 & 30.38 & 49 & 24.5 & 38 & 31.4 & \\
\hline Friends & 14 & 17.72 & 34 & 17 & 8 & 6.61 & \\
\hline TV & 7 & 8.86 & 27 & 13.5 & 6 & 4.96 & \\
\hline Awareness campaigns & 12 & 15.19 & 35 & 17.5 & 54 & 44.63 & \\
\hline Other & 7 & 8.86 & 14 & 7 & 0 & 0 & \\
\hline More than one & 2 & 2.53 & 11 & 5.5 & 8 & 6.61 & \\
\hline \multicolumn{8}{|l|}{ Cancer in family } \\
\hline Yes & 12 & 15.19 & 19 & 9.5 & 9 & 7.44 & \multirow{2}{*}{3.310 .192} \\
\hline No & 67 & 84.81 & 181 & 90.50 & 112 & 92.56 & \\
\hline
\end{tabular}

Table 5. Continued.

\begin{tabular}{|c|c|c|c|c|c|}
\hline \multirow{4}{*}{ Characteristics } & \multicolumn{5}{|c|}{ Total knowledge level $(n=400)$} \\
\hline & \multicolumn{4}{|c|}{ Post } & \multirow{3}{*}{$\chi^{2} \mathbf{P}$} \\
\hline & \multicolumn{2}{|c|}{ Fair $(n=26)$} & \multicolumn{2}{|c|}{ Good $(n=374)$} & \\
\hline & $\mathbf{N}$ & $\%$ & $\mathbf{N}$ & $\%$ & \\
\hline \multicolumn{6}{|l|}{ School } \\
\hline Private & 13 & 50 & 187 & 50 & \multirow{2}{*}{ FE 1} \\
\hline Government & 13 & 50 & 187 & 50 & \\
\hline \multicolumn{6}{|l|}{ Age (in years) } \\
\hline 17 years & 22 & 84.62 & 224 & 59.89 & \multirow{3}{*}{$6.290 .043 *$} \\
\hline 18 years & 4 & 15.38 & 148 & 39.57 & \\
\hline 19 years & 0 & 0 & 2 & 0.53 & \\
\hline \multicolumn{6}{|l|}{ Sources of knowledge } \\
\hline None & 7 & 26.92 & 43 & 11.5 & \multirow{7}{*}{$44.750 .00 *$} \\
\hline Net & 0 & 0 & 111 & 29.68 & \\
\hline Friends & 6 & 23.08 & 50 & 13.37 & \\
\hline TV & 9 & 34.62 & 31 & 8.29 & \\
\hline Awareness campaigns & 0 & 0.00 & 101 & 27.01 & \\
\hline Other & 4 & 15.38 & 17 & 4.55 & \\
\hline More than one & 0 & 0 & 21 & 5.61 & \\
\hline \multicolumn{6}{|l|}{ Cancer in family } \\
\hline Yes & 0 & 0 & 40 & 10.70 & \multirow{2}{*}{ FE 0.093} \\
\hline No & 26 & 100 & 334 & 89.30 & \\
\hline
\end{tabular}

* Significant at $\mathrm{P}<0.05$.

Table 6. Correlation between socio demographic characteristics of the studied students and their total level of attitude regarding breast cancer pre and post the educational intervention.

\begin{tabular}{|c|c|c|c|c|c|c|c|c|}
\hline \multirow{4}{*}{ Characteristics } & \multicolumn{8}{|c|}{ Total attitude and perception level $(n=400)$} \\
\hline & \multicolumn{4}{|c|}{ Pre } & \multirow{3}{*}{$\chi^{2} \mathbf{P}$} & \multirow{2}{*}{\multicolumn{2}{|c|}{$\begin{array}{l}\text { Post } \\
+ \text { ve attitude }(n=400)\end{array}$}} & \multirow{3}{*}{$\chi^{2} \mathbf{P}$} \\
\hline & \multicolumn{2}{|c|}{-ve attitude $(n=17)$} & \multicolumn{2}{|c|}{ +ve attitude $(n=383)$} & & & & \\
\hline & $\mathbf{N}$ & $\%$ & $\mathbf{N}$ & $\%$ & & $\mathbf{N}$ & $\%$ & \\
\hline \multicolumn{9}{|l|}{ School } \\
\hline Private & 15 & 88.24 & 185 & 48.3 & \multirow{3}{*}{ FE $0.002 *$} & 200 & 50 & \multirow{3}{*}{-} \\
\hline Government & 2 & 11.76 & 198 & 51.7 & & 200 & 50 & \\
\hline \multicolumn{7}{|l|}{ Age (in years) } & & \\
\hline 17 years & 2 & 11.76 & 244 & 63.71 & \multirow{3}{*}{$19.020 .00 *$} & 246 & 61.5 & \multirow{3}{*}{-} \\
\hline 18 years & 15 & 88.24 & 137 & 35.77 & & 152 & 38 & \\
\hline 19 years & 0 & 0 & 2 & 0.52 & & 2 & 0.5 & \\
\hline \multicolumn{9}{|c|}{ Sources of knowledge } \\
\hline None & 7 & 41.18 & 43 & 11.23 & \multirow{4}{*}{$27.770 .00^{*}$} & 50 & 12.5 & \multirow{4}{*}{-} \\
\hline Net & 0 & 0 & 111 & 28.98 & & 111 & 27.8 & \\
\hline Friends & 0 & 0 & 56 & 14.62 & & 56 & 14 & \\
\hline TV & 5 & 29.41 & 35 & 9.14 & & 40 & 10 & \\
\hline
\end{tabular}




\begin{tabular}{|c|c|c|c|c|c|c|c|c|}
\hline \multirow{4}{*}{ Characteristics } & \multicolumn{8}{|c|}{ Total attitude and perception level $(n=400)$} \\
\hline & \multicolumn{4}{|c|}{ Pre } & \multirow{3}{*}{$\chi^{2} \mathbf{P}$} & \multirow{2}{*}{\multicolumn{2}{|c|}{$\begin{array}{l}\text { Post } \\
+ \text { +ve attitude }(n=400)\end{array}$}} & \multirow{3}{*}{$\chi^{2} \mathbf{P}$} \\
\hline & \multicolumn{2}{|c|}{-ve attitude $(n=17)$} & \multicolumn{2}{|c|}{ +ve attitude $(n=383)$} & & & & \\
\hline & $\mathbf{N}$ & $\%$ & $\mathbf{N}$ & $\%$ & & $\mathbf{N}$ & $\%$ & \\
\hline Awareness campaigns & 5 & 29.41 & 96 & 25.07 & & 101 & 25.3 & \\
\hline Other & 0 & 0 & 21 & 5.48 & & 21 & 5.3 & \\
\hline More than one & 0 & 0 & 21 & 5.48 & & 21 & 5.3 & \\
\hline Yes & 0 & 0 & 40 & 10.44 & \multirow{2}{*}{ FE 0.396} & 40 & 10 & \multirow{2}{*}{-} \\
\hline No & 17 & 100 & 343 & 89.56 & & 360 & 90 & \\
\hline
\end{tabular}

* Significant at $\mathrm{P}<0.05$.

Table 7. Correlation between socio-demographic characteristics of the studied student and total mean scores of both knowledge and attitude toward breast cancer pre and post-intervention.

\begin{tabular}{|c|c|c|c|c|c|c|c|c|}
\hline \multirow{3}{*}{ Characteristics } & \multicolumn{4}{|c|}{ Total attitude score } & \multicolumn{4}{|c|}{ Total knowledge score } \\
\hline & \multicolumn{2}{|c|}{ Pre } & \multicolumn{2}{|l|}{ Post } & \multicolumn{2}{|c|}{ Pre } & \multicolumn{2}{|l|}{ Post } \\
\hline & $\mathbf{r}$ & $\mathbf{P}$ & $\mathbf{r}$ & $\mathbf{P}$ & $\mathbf{r}$ & $\mathbf{P}$ & $\mathbf{r}$ & $\mathbf{P}$ \\
\hline Age (in years) & -0.204 & $0.00 * *$ & -0.108 & $0.031 *$ & -0.053 & 0.288 & 0.178 & $0.00 * *$ \\
\hline \multicolumn{9}{|l|}{ School } \\
\hline Private & -0.212 & \multirow{2}{*}{$0.00 * *$} & -0.088 & \multirow{2}{*}{0.08} & -0.187 & \multirow{2}{*}{$0.00 * *$} & 0.107 & \multirow{2}{*}{$0.032 *$} \\
\hline Government & 0.212 & & 0.088 & & 0.187 & & -0.107 & \\
\hline
\end{tabular}

* Correlation is significant at level $\mathrm{P}<0.05$.

**Correlation is highly significant at level $\mathrm{P}<0.01$

\section{References}

[1] Kilpi F, Webber L, Musaigner A, Aitsi-Selmi A, Marsh T, Rtveladze K, McPherson K, Brown M. Alarming predictions for obesity and non-communicable diseases in the Middle East. Public health nutrition. 2014 May; 17 (5): 1078-86.

[2] Boyle P, Levin B. World cancer report 2008. IARC Press, International Agency for Research on Cancer; 2008.

[3] Shalini Saggu, Hasibur Rehman, Zahid K. Abbas, and Abid A. Ansari, Recent incidence and descriptive epidemiological survey of breast cancer in Saudi Arabia. Saudi Med J. 2015 Oct; 36 (10): 1176-1180. doi: 10.15537/smj. 2015.10.12268.

[4] World Health Organization. Country cooperation strategy for WHO and Saudi Arabia 2012-2016. World Health Organization. Regional Office for the Eastern Mediterranean; 2013.

[5] O'Mahony, M., Comber, H., Fitzgerald, T., Corrigan, M. A., Fitzgerald, E., Grunfeld, E., \& Hegarty, J. (2017). Interventions for raising breast cancer awareness in women. The Cochrane Library. Cochrane Database of Systematic Reviews 2014, Issue 12. Art. No.: CD011396.

[6] Brown R, Kerr K, Haoudi A, Darzi A. Tackling cancer burden in the Middle East: Qatar as an example. Lancet Oncol. 2012; 13: e501-e508. [PubMed].

[7] Keten HS, Yıldırım F, lmez S, -çer H, lelik M. Knowledge, attitudes and behavior about breast cancer in women presenting to Early Cancer Diagnosis, Screening and Education Centre in Kahramanmaraş, Turkey. Gaziantep Medical Journal 2014; 20: 46.
[8] Azaiza F, Cohen M, Awad M, Daoud F. Factors associated with low screening for breast cancer in the Palestinian Authority: relations of availability, environmental barriers, and cancer-related fatalism. Cancer 2010; 116: 4646-4655.

[9] WHO, EMRO. Guidelines for the early detection and screening of breast cancer: a quick reference guide. Cairo: WHO, EMRO; 2006 (EMRO Technical Publications Series No 30).

[10] Ferlay J, Shin HR, Bray F et al. Estimates of worldwide burden of cancer in 2008. Int J Cancer 2010; 127: 2893-917.

[11] Al Otaibi S, Al Harbi M, Al Kahmoas A, Al Qhatani F, Al Mutairi F, Al Mutairi T, Al Ajmi R, Al Mousawi F. General breast cancer awareness among women in Riyadh city. Asian Pacific journal of cancer prevention: APJCP. 2017; 18 (1): 159.

[12] Sapkota D, Parajuli P, Kafle T. Effectiveness of Educational Intervention Programme on Knowledge Regarding Breast Self Examination Among Higher Secondary School Girls of Biratnagar Birat Journal of Health Sciences Vol. 1/No. 1/Issue 1/ Sept-Dec 2016.

[13] Zeinomar, N., \& Moslehi, R. (2013). The effectiveness of a community-based breast cancer education intervention in the New York State Capital Region. Journal of Cancer Education, 28 (3), 466-473.

[14] Gucuk S, Uyeturk (2013) Effect of direct education on breast self-examination awareness and practice among women in Bolu, Turkey. Asian Pacific Journal of Cancer Prevention 14 (12): 7707-7711.

[15] Mortada, Emam M, Safie EI, Omnia S (2013) Effectiveness of health education intervention on improving breast selfexamination among female teacher: Applying health belief model. The Egyptian Journal of Community Medicine 31 (4): 17-40. 
[16] Hay S, Mohamed N (2015) Effect of educational program about breast cancer knowledge and breast self-examination training on building accurate information and behavior among women. Journal of Natural Sciences Research 5 (4): 58-70.

[17] Hacihasanoglu R, Gozum S (2008) The effect of training on the knowledge levels and beliefs regarding breast selfexamination on women attending a public education centre. Eur J Oncol Nurs 12: 58-64.

[18] Rezaeian M, Sharifirad GH, Mostafavi F, Moodi M, Abbasi MH (2014) The effects of breast cancer educational intervention on knowledge and health beliefs of women 40 years and older, Isfahan, Iran. J Edu Health Promot 3: 59-64.

[19] Haghighi F, Hoseini SM, Eshaghi S, Naseh GH, Tavakoli MR (2015) The effects of education on breast self-examination knowledge, attitude, and practice among the female employees of Birjand University. Mod Care J 12 (1): 47-53.

[20] Masso C \& Meneses E \& Correa Bautista Effects of an Educational Intervention on Breast Self-Examination, Breast Cancer Prevention-Related Knowledge, and Healthy Lifestyles in Scholars from a Low-Income Area in Bogota, Colombia $J$ Canc Educ DOI 10.1007/s13187-016-1133-z 2016.

[21] Akhtari M, Juni M, Said S, Ismail I, Latiff L, Ataollahi E (2016) Result of randomized control trial to increase breast health awareness among young females in Malaysia. BMC Public Health 16: 738.
[22] Bawtinhimer A, Bosellib D, Magbis L, Nury S, James S. Outcomes of a structured education intervention for Latinas concerning breast cancer and mammography Health Education Journal 2017, Vol. 76 (4) 442-453.

[23] Masoudiyekta L, Rezaei $\mathrm{H}$ et al. Effect of Education Based on Health Belief Model on the Behavior of Breast Cancer Screening in Women Asia Pac J OncolNurs. 2018 Jan-Mar; 5 (1): $114-120$.

[24] Kashfi S, Jeihooni A, Yazdankhah M (2009) The effect of education about breast self-examination on knowledge, attitude, and practice of women in Nourabad Mamasami health clinics. Journal of Jahrom University of Medical Science 10 (1): 36-40.

[25] Moussa M, Shalaby N (2014) Effect of breast selfexamination education program on knowledge, attitude and practice of nursing students. International Journal of Research Studies in Bioscience 2 (6): 40-49.

[26] Rehena J, Hossain A and RaziaS Educational Intervention to Improve Breast Self- Examination Practice among Women: Evidence-Based-Practice. $J O$ nursing and health care Volume 7 Issue 3- April 2018 DOI: 10.19080/JOJNHC. 2018.07.555712.

[27] Syamilah M, Norfidah M. Effectiveness of a health education intervention for breast cancer prevention among women $e$ Journal Penyelidi kandan Inovasi Vol. III, No. I (April 2016) 103 - 122 e-ISSN 2289-7909. 